\section{Risk of systemic lupus erythematosus in patients with idiopathic thrombocytopenic purpura: population-based cohort study}

We read with great interest the article by Zhu et al. ${ }^{1}$ It was based on a national study regarding the association between idiopathic thrombocytopenic purpura (ITP) and the subsequent development of systemic lupus erythematosus (SLE), both representing clinically and genetically heterogeneous autoimmune diseases. According to the data presented in this study, the authors demonstrated that the patients with ITP had a 26 times higher risk of new-onset SLE in comparison with the control population. ${ }^{1}$ Prevalence of ITP has been reported to be ranging between $7 \%$ and $30 \%$ in patients with SLE, while clinical characteristics of ITP in patients with SLE have been reported in several studies. ${ }^{2}$ ITP is a haematological disorder characterised by thrombocytopenia, defined by low platelet counts, thus presenting with an increased bleeding risk due to an increased destruction of sensitised platelets by antibodies that react with glycoproteins expressed on platelets and megakaryocytes. ${ }^{3}$

Furthermore, this study by Zhu et $a l^{1}$ poses the intriguing question concerning the putative role of a shared genetic background as regards with the concurrence of ITP and SLE, an issue also discussed recently by Fanouriakis et al. ${ }^{4}$ Thus, although the main cause of ITP and SLE remains unidentified, various studies have pointed to certain polymorphisms in respective genes as potential factors for developing both ITP and SLE, thus suggesting a shared genetic predisposition in some cases. According to McGarvey et al,,$^{5} 41$ pathways are shared by ITP and SLE, and 27 genes are associated with both diseases. Moreover, a list of genetic polymorphisms leading to exacerbation of the disease in patients with ITP, such as IL-10-592C/A, IL-4 VNTR, IL-17F rs763780, IL-6-174 G/C and interferon (IFN)-gamma $874 \mathrm{~T} / \mathrm{A}$, has been presented, with these factors also being associated with an increased risk of SLE ${ }^{67}$ Notably, studies comparing molecular signatures of these two diseases do not seem to be promiscuous as regards the identification of a disease-specific signature, considering that a global expression profile of peripheral blood from patients with ITP identified an ITP-specific signature, which also included IFN-induced genes that have been observed in SLE as well. ${ }^{8}$

In conclusion, lessons learnt thus far from the genetic studies focusing on ITP and SLE suggest that the biological complexity of these diseases should not be underestimated, considering that identical gene variants have been previously associated with different clinical phenotypes, while, conversely, a significant clinical and molecular overlap has been identified between patients with mutations in different genes. ${ }^{9}$
George N Goulielmos • , Maria I Zervou

Department of Internal Medicine, Laboratory of Molecular Medicine and Human Genetics, University of Crete, Heraklion, Greece

Correspondence to Dr George N Goulielmos, Department of Medicine, University of Crete, Heraklion 715 00, Greece; goulielmos@med.uoc.gr

Contributors GNG wrote the paper. MIZ reviewed and edited the manuscript. All authors read and approved its final form.

Funding The authors have not declared a specific grant for this research from any funding agency in the public, commercial or not-for-profit sectors.

Competing interests None declared.

Patient and public involvement Patients and/or the public were not involved in the design, conduct, reporting or dissemination plans of this research.

Patient consent for publication Not required.

Provenance and peer review Not commissioned; internally peer reviewed.

(c) Author(s) (or their employer(s)) 2020. No commercial re-use. See rights and permissions. Published by BMJ.

\section{Check for updates}

To cite Goulielmos GN, Zervou MI. Ann Rheum Dis Epub ahead of print: [please include Day Month Year]. doi:10.1136/annrheumdis-2020-218128

Received 27 May 2020

Accepted 29 May 2020

\section{Linked}

- http://dx.doi.org/10.1136/annrheumdis-2020-218177

Ann Rheum Dis 2020;0:1. doi:10.1136/annrheumdis-2020-218128

ORCID ID

George N Goulielmos http://orcid.org/0000-0002-9797-2310

\section{REFERENCES}

1 Zhu F-X, Huang J-Y, Ye Z, et al. Risk of systemic lupus erythematosus in patients with idiopathic thrombocytopenic purpura: a population-based cohort study. Ann Rheum Dis 2020:annrheumdis-2020-217013.

2 Ziakas PDet al. Lupus thrombocytopenia: clinical implications and prognostic significance. Ann Rheum Dis 2005;64:1366-9.

3 Iraqi M, Perdomo J, Yan F, et al. Immune thrombocytopenia: antiplatelet autoantibodies inhibit proplatelet formation by megakaryocytes and impair platelet production in vitro. Haematologica 2015;100:623-32.

4 Fanouriakis A, Bertsias G, Boumpas DT. Population-based studies in systemic lupus erythematosus: immune thrombocytopenic purpura or 'blood-dominant' lupus? Ann Rheum Dis 2020:annrheumdis-2020-217356.

5 McGarvey PB, Suzek BE, Baraniuk JN, et al. In silico analysis of autoimmune diseases and genetic relationships to vaccination against infectious diseases. BMC Immunol 2014;15:61.

6 Lee YH, Bae S-C. Association between interferon- $\gamma+874$ T/A polymorphism and susceptibility to autoimmune diseases: a meta-analysis. Lupus 2016;25:710-8.

7 Rischewski JR, Imbach P, Paulussen M, et al. Idiopathic thrombocytopenic purpura (ITP): is there a genetic predisposition? Pediatr Blood Cancer 2006;47:678-80.

8 Sood R, Wong W, Gotlib J, et al. Gene expression and pathway analysis of immune thrombocytopenic purpura. Br J Haematol 2014;140:99-103.

9 Demirkaya E, Sahin S, Romano M, et al. New horizons in the genetic etiology of systemic lupus erythematosus and lupus-like disease: monogenic lupus and beyond. $J$ Clin Med 2020;9:712. 